\title{
Acquisition of Adjective Placement by L3 Learners of English: Evidence for the L2 Status Factor
}

\author{
Maryam Ghezlou*, Mansour Koosha, Ahmad Reza Lotfi \\ Department of Foreign Languages, Isfahan (Khorasgan) Branch, Islamic Azad University, Iran \\ Corresponding Author: Maryam Ghezlou, E-mail: Maryam.ghezlou@gmail.com
}

\section{ARTICLE INFO}

\section{Article history}

Received: November 15, 2017

Accepted: January 24, 2018

Published: March 01, 2018

Volume: 7 Issue: 2

Advance access: February 2018

Conflicts of interest: Non

Funding: None

\begin{abstract}
This study attempts to tease apart the effect of first (L1) and second (L2) language knowledge on the acquisition of syntactic properties of L3 English in order to test current generative theories in the field of third language acquisition (L3A). The property under investigation is adjective placement. Participants are L1 Azeri / L2 Persian, and L1 Persian learners of English as a third and second language respectively. To fulfill so, 180 bilingual and monolingual university students from Arak and Miyandoab took a general English proficiency test, a background questionnaire, and a syntactic structure test. The L3 proficiency was also considered. The data, then, were analyzed through utilization of descriptive statistics and two-way ANOVA. In relation to the hypotheses, results indicated L2 status as the determining factor in the acquisition of English adjective properties by Azeri-Persian bilinguals. Proficiency level in the L3 also proved to have a significant role. The implications of the study can be utilized in developing an educational and linguistic methodology for bilingual learners of English as an L3 in Iran.
\end{abstract}

Key words: Azeri, Bilingual, L2 Status, L3 Proficienc , Persian, Typology, Third Language Acquisition

\section{INTRODUCTION}

The last two decades have witnessed a flourishing interest in the acquisition of a third language (L3A). The prominent scholars in the field (Cenoz, 2008, 2009; Cenoz \& Genese, 1998; Cenoz \& Jessner, 2001; De Angelis, 2007; Falk \& Bardel, 2010, 2011; Flynn, Foley, Vinniyetska, 2004; Rothman, 2010, 2011) presume the presence of qualitative differences between L3A and that of second language acquisition (L2A), since the new field was once subsumed under the L2 acquisition studies. Cenoz (2003) and Cenoz and Jessner (2000), for instance, claim that the L3 learner, in addition to the first language (L1), has obtained an L2 which could undoubtedly play a role in the acquisition of the target language (L3, L4, or Ln) while L2 acquirer can only resort to his L1 in the acquisition of an L2. The production, comprehension, and development of a target language, hence, can be influenced by prior language knowledge. The phenomenon known as cross-linguistic influence (CLI) is a hotly debated topic in this regard and has been claimed to be in sharp contrast with the more archaic term of 'transfer'.

According to De Angelis (2007, p. 21) transfer can be viewed as a one-to-one type of association, that is, the association between the source and target language. CLI, on the other hand, is of the many-to-one type of association which entails the simultaneous influence of more than one language (L1 or L2) upon the target language. In this regard, while some studies found supporting evidence in the privileged role of L2 in the acquisition of a third language,
(L2 Status Factor Hypothesis, Bardel \& Falk, 2007; Falk \& Bardel, 2011), other studies hypothesize that all background languages can have an equal impact, that is, Cumulative Enhancement Model (CEM, Flynn, Foley, Vinniyetska, 2004), and Typological Primacy Model (TPM, Rothman, 2010, $2011,2013,2015)$. In the present study of the acquisition of English adjective placement, these three syntactic hypotheses will be tested on two groups of Azeri-Persian bilinguals and Persian monolinguals who are learning English as an L3 and L2 respectively. This language combination can be ideal for determining the source of CLI in the acquisition of L3 syntactic properties since Azeri and English, despite being distant languages, show structural similarity in placing the adjectives. In more precise terms, attributive adjectives are placed before their complementing nouns, while Persian, in spite of its genetic relatedness to English (Indo-European language family) depicts post-nominal positioning of adjectives. Bilingual learners are predicted to take advantage of such overlap between their L1 and L3, and hence perform better on the syntactic test (TPM). The contradictory result, on the contrary, would signify L2 Persian as the determining source of CLI in the acquisition of adjective placement.

CLI, has also been purported to be influenced by various factors including proficiency in both L2 and L3 (Tremblay, 2006; Bardel \& Lindqvist, 2007; De Angelis, 2007; Lindqvist, 2010), context (Dewaele, 2001); recency of use of a particular language (Hammarberg, 2001), and the typological similarity between the previously learnt languages and 
the third one (De Angelis \& Selinker, 2001; Cenoz, 2001; Rothman, 2010, 2011, 2015). The present study, in line with previous studies (Kujalowics, 2005; Lindqvist, 2009; Naves, Miralpeix, \& Celaya, 2005; Ortega, 2008) pays particular attention to L3 proficiency level, and makes an endeavor to see whether increase in L3 proficiency level leads to lower occurrence of CLI among bilinguals. It further attempts to determine the interaction between L3 proficiency level and the participants' native language.

The following section provides more details on the syntactic models of LSFH, CEM, and TPM, in addition to the syntax of the three languages involved; Azeri, Persian and English. A review of the related literature will be provided in the next section. What comes next is methodology, i.e. participants, materials, procedure and results. Findings will be discussed in section 7 and finall, the conclusion will be the final section dealt with in the present stud .

\section{THEORETICAL FRAMEWORK}

The very first model of L3A was introduced by Flynn, Foley and Vinnitskaya in 2004. In their study they examined the production of restrictive relative clauses in L1 Kazakh / L2 Russian/L3 English speakers. Considering L1 as the default for all subsequent language acquisition, and typological differences as the sole determiners of language development, they proposed that L3 acquisition of English by L1 speakers of Kazakh should resemble L2 acquisition of English by L1 speakers of Japanese since Kazakh and Japanese shared the same head direction. Their finding demonstrated the L1 was not the privileged source of CLI at the level of syntactic features and functional categories, but L2 can be source as well. As its name suggests, language learning is cumulative and all previously experienced languages may influence the development of subsequently acquired languages. In other words, all previously acquired linguistic features are in theory available to the L3 learners CLI, in this case, is predicted not to be random, but highly facilitative. The model argues that any prior language knowledge can enhance later language development or remain neutral. Transfer can occur only when the previous language knowledge has a positive influence. Despite this, CLI will never happen.

L2 Status Factor Hypothesis (LSFH) (Bardel \& Falk, 2007; Falk \& Bardel, 2011) maintains that the L2 takes on a significantly stronger role than the L1 in the initial state of L3 morphosyntax. It focuses on the obvious differences between L1 and the subsequently learnt languages and predicts a general tendency to activate and transfer linguistic experience and/or elements of the last learned language into subsequent language acquisition. In an effort to test the hypothesis that the L2 serves as the strongest source of CLI, Bardel and Falk (2007) studied two groups with different L1s and L2s who acquired Swedish and Dutch as L3s, focusing on the placement of negation. Results indicated the transfer of L2 word order into the L3. They concluded that typology might have played a role in CLI but L2 played a stronger role in transferring in L3. Bardel and Falk, furthermore, suggested that L2 status factor contributed to syntactic transfer not only in the initial state of learning an L3 but also in subsequent states.

Typological Primacy Model (Rothman, 2010, 2011, 2015) shares the idea with CEM on the ground that neither the L1 nor the L2 play a privileged role in the L3 morphosyntactic transfer. The model, indeed, focuses on the actual typological similarities or the perceived typological similarities (known as (psycho)-typological primacy) of the L3 and all previously learned languages. Unlike CEM, the TPM predicts the non-facilitative transfer stemming from a (psycho)-typologically motivated misanalysis of which language's underlying syntax, L1 or L2, should be used in the L3. To test the hypothesis, Rothman (2011) examines two groups of L1 Italian/L2 English learners of Spanish as L3 and L1 English/L2 Spanish learners of Portuguese as L3 with a focus on DP structure. The data revealed that L3 Spanish learners transferred from their L1 Italian whereas the Brazilian Portuguese learners relied on their L2 Spanish, not their L1 English. Both transfer sources are (psycho)-typologically similar to the L3, unlike English, a non-Romance language (Hermas, 2010).

The present study makes an endeavor to test the three generative models of CEM, LSFH, and TPM in order to determine which theory can best account for the possible transfer of L1 Azeri or L2 Persian adjective properties in the acquisition of English as an L3. The number of studies conducted on this property seem to be quite scanty (Khodabandeh, 2013; Fallah \& Jabbari, 2007) and such fact justifies conducting new lines of research on this area.

\section{LITERATURE REVIEW}

Despite the growing body of literature on generative aspects of L3 acquisition in the world (e.g. Berkes \& Flynn, 2012; Cenoz, 2009; Dias \& Santos, 2011; Hermas, 2015; Jaensch, 2010; Jin, 2009; Montrul, Rothman, \& Cabrieli Amaro, 2010; Rothman, 2011, 2015; Slabakova \& Garcia, 2015; Westergaard, Mitrofanova, Mykhaylyk, \& Rodina, 2016), the number of L3A generative studies conducted in Iran has been very infinitesimal

Khodabandeh (2013), focusing on two competing approaches to adult language acquisition, so-called Failed Functional Features approaches (FFFAs) (Franceschina, 2001) and Full Access approaches (FAAs) (Schwartz \& Sprouse, 1996), examined the L3 initial state of three types of groups of L3 learners of English such as Azerbaijani Persian, Armenian -Persian and Gilaki- Persian bilinguals via knowledge of adjective order. The instrument of the study was a grammatical test which consisted of three parts. The findings of the study were in accordance with the predictions of (FFFH) hypothesis where L1 transfer being hypothesized. L3 learners performed significantly higher than L2 learners as their interlanguage grammar seemed to reflect more of the parameter values of their L1s.

Ghooniband Shooshtari (2009) investigated the acquisition of two syntactic properties of head and operator movements in English by L2 and L3 learners within UG framework. The participants consisted of 144 Persian monolingual and Arabic-Persian bilingual learners of English who were 
assigned to three proficiency bands after taking the general proficiency test (ECPE). No significant difference was observed between the performance of monolinguals and bilinguals at each level of proficienc . Results led her to the conclusion that bilingualism presents no significant advantage in third language acquisition.

Recently two more pertinent studies have been conducted by Jabbari and Salimi (2015) and Fallah and Jabbari (2017), although source languages are different.

The first study (Jabbari \& Salimi, 2015) investigated the role of previously acquired languages based on the generative models of CEM, TPM, and LSFH at the initial stage of acquisition of English simple present and present continuous by Turkmen-Persian bilinguals and Persian monolinguals. Turkmen and Persian overlap on the simple present while with respect to present continuous it is Persian which shows dissimilarity. The instruments used implemented in their study were GJT as well as two translation tasks. Findings revealed the main effect of Turkmen $\mathrm{L} 1$ on the acquisition of syntactic properties in the study.

Focusing on the same generative theories of third language acquisition, the second study (Fallah \& Jabbari, 2017) assessed the role of Mazadndarani L1 and Persian L2 on the acquisition of attributive adjectives among three bilingual groups of Mazandarani L1/Persian L2 with Mazandarani as the dominant language, Mazandarani L1/Persian L2 with Persian as the dominant language, and Persian L1/Mazandarani L2. In Mazani and English, attributive adjectives precede the head noun whereas in Persian they are postponed. None of the theories tested, however, account for the CLI in the third language of the participants. The researchers, nonetheless, introduced language of communication as the source of transfer in this respect.

Taken together, the studies discussed above do not concord on the source of CLI in the acquisition of L3 syntactic properties. The present study makes an attempt to shed more light on the issue by comparing the acquisition of adjective placement and the probable role of L3 proficiency by Azeri-Persian bilinguals and Persian monolinguals. The following research questions and hypotheses are formulated based on the discussions made above.

\section{RESEARCH QUESTIONS AND HYPOTHESES}

The following research questions and hypotheses were formulated based on the objectives of the present study.

Q1. Does the knowledge of adjective placement in Azeri L1 affect the performance on Farsi-to-English translation by bilingual Azeri-Persian learners significantly more than monolingual EFL learners?

Q2. Does proficiency level in the English L3 affect the performance of Azeri-Persian bilinguals in the acquisition of adjective placement?

Q3. Do proficiency levels significantly interact with the effect of mother languages (monolingual vs. bilingual)?

Ho1. The knowledge of adjective order and placement in Azeri L1 does not affect the performance on Farsi-to-English translation by bilingual Azeri-Persian learners significantly more than monolingual EFL learners.
Ho2. Proficienc level in the English L3 does not affect the performance of Azeri-Persian bilinguals in the acquisition of adjective properties.

Ho3. Proficiency levels will not significantly interact with the effect of mother languages (monolingual vs. bilingual).

\section{ADJECTIVE PLACEMENT: CROSS-LINGUISTIC DIFFERENCES}

The three languages involved in the present study show certain similarities and dissimilarities in several respects. Typologically speaking, Persian and English share the same family group (Indo-European), whereas Azeri belongs to the family of Altaic languages which host Turkic, Mongolic, and Tungusic languages. As the dominant minority language in northwestern parts of Iran (Erfani, 2012), Azeri is spoken with more than 20 million speakers (Crystal, 2010) throughout the country.

With respect to word order, Azeri and Persian, as prodrop languages exhibit SOV order. English, on the other hand, is a SVO language in which the presence of subject is necessary. Persian and Azeri, in addition, are considered as free word order languages, hence subjects can be omitted (Shomoossi, Shomoossi, \& Yazdi, 2013).

With respect to noun phrases (NPs), both English and Persian are head-first while Azeri is more head-last (Shomoossi, et al. 2013). In Persian, the head noun in an NP is often followed by modifiers including adjectives, and this process is usually accompanied by adding -e (Ezafe construction)

An dokhtar-e (Ez) ziba (Persian)

A girl-e (Ez) beautiful

Regarding the placement of adjectives and modifiers, however, Azeri and English behave the same that is all the modifiers including adjectives are located pre-nominally

Bir guzel qiz (Azeri)

A beautiful girl (English)

An adjective is used attributively when it comes before a noun, and is therefore part of the noun phrase. Predicative adjectives, on the other hand, are those adjectives which come directly after verbs such as be, seem, look, etc., as the complement. What concerns the present study is the acquisition of attributive adjectives.

All in all, since Azeri (L1) and English (L3) are similar with respect to adjective placement, the knowledge of Persian (L2) on the part of the subjects would be the a reason if they produce ungrammatical phrases such as below

*The girl beautiful

\section{METHOD}

\section{Participants}

Participants of the present study were chosen from a large pool of students from both genders studying English as a foreign language at university. Bilingual group, including 90 participants with Azeri as their L1 and Persian as their L2, had acquired Azeri as their mother tongue naturally in the home environment. Persian, on the other hand, was intro- 
duced to their linguistic repertoire from the age 7, and continued as the language of instruction up to diploma. Monolingual learners like bilinguals had learned Persian formally from the age 7 onwards. In order to ensure the homogeneity of participants prior to the study, they took Preliminary English Test (PET, 2015) as the general English proficiency test, and it was found that they had almost the same means. The test was further used to assign each group into 3 proficiency levels of high, mid and low. Bilingual learners were learning English as an L3 at Azad university of Miyandoab, an Azeri speaking city in the north west of Iran, while monolinguals were studying English as an L2 at Arak, a Persian speaking city in central Iran.

\section{Tasks}

The instruments administered in the present study were as following: (a) a multi-section questionnaire; (b) a proficie cy test; and (c) a translation test. A pilot study was conducted to see how well the tests and the questionnaire worked. Some test items and questionnaire items were deleted based on the results of item analysis. They were presented to the participants in three occasions in the spring semester of the 2015-2016 academic year.

\section{Questionnaire}

The questionnaire which was utilized in the present study was extracted from a more comprehensive questionnaire devised by Moghtadi (2014) based on McCuiston and Spellerberg's (2006) study and Sing-Chi's (2011) study. It included two sections, i.e. 'Background Information' and 'Language Information'. The first section required demographic information about the participants. The second section, i.e. 'Language Information' required the subjects to provide some information regarding the educational level of their parents, their families' native languages, the number of years that they had received education in their L1, L2 and possibly L3 language (s), and their city of origin In order to maximize the reliability and validity of the collected data, participants were encouraged to express their actual viewpoints on the items by informing them that their responses had nothing to do with their academic records. The questionnaire, furthermore, was piloted and some items were deleted or revised prior to the actual administration of the questionnaire to ensure that the meanings of the items were appropriate. It was also written in Persian in order to avoid participants' English proficiency impinging upon their ability to fill in questionnaire, as, for instance, the bilingual group did not receive any education in their native language, and, therefore, could not read in their L1 Azeri.

\section{General proficiency test}

In this study, Preliminary English Test (PET, 2015 version), a Cambridge University Exam that tests one's ability to cope with every day written and spoken communications (Modirkhameneh, 2008) was utilized. The purpose of using this test was twofold. First, it was utilized to make sure of the ho- mogeneity of the participants in terms of English proficiency level. And second, it was utilized to place the participants at appropriate level of English proficienc , i.e. low, mid, high.

PET has three sections: Reading and Writing, listening, and speaking. Due to some practical limitations, the speaking and writing sections were not administered. It consisted of 50 multiple choice, true / false, and fill-in-the-blanks items with an estimated time of 80 minutes for completion as determined in the PET. It was a paper-and-pencil test and participants had to answer the questions on specified answer sheets.

\section{Translation task}

A Persian-to-English translation test was devised for the purpose of the present study. In other words, through this test, it was intended to diagnose to what extent participants' performance was influenced by their first language (monolingual group) or their second language (bilingual group). Translation tasks have been endorsed by some researchers as production tests in various L3 studies (Gooniband Shooshtari, 2009; Jabbari \& Salimi, 2015; Khodabandeh, 2013, 2015; Modirkhameneh, 2008, to name a few)

The preparation of the test was done in three stages: initially it was decided to include items on adjective placement. Secondly, for adjective placement only attributive adjectives were considered and approximately twenty sentences were devised. The final test consisted of fifteen sentences assessing adjective placement plus five distractors

- Example

Ali yek kif-e siyah kharid

Ali a bag-EZ black bought

Ali bought a black bag

\section{PROCEDURE AND SCORING}

The data collection procedure consisted of presentation of a questionnaire, a general English proficiency test, and a translation task. After carrying out the sampling procedure and choosing groups, as the first step, the researcher used oral description to explain the study to the students, giving brief instructions for all phases of the study. She reiterated that participants should not see the experiment as a 'test'. The questionnaire was then distributed. During the second week, both monolingual and bilingual participants took the general proficiency test. The test was administered according to the test instructions including strict time limits ( 80 minutes). Based on the results of PET, each group was further divided into low, mid, and high proficiency groups. Finally, in week four, both groups took the translation test within a time-limit of 25 minutes.

For scoring the translation test, one point was assigned for the individual sentences that were structurally correct, but no point was given to the structurally incorrect sentences. In other words, each correct response, the one in which adjective placement were observed- was awarded a score of one, whereas wrong or blank responses were given no point, that is, the score of zero. Lexical errors, if any, were ignored as they were not of any importance in the research study. 


\section{RESULTS}

A two-way analysis of variances (two-way ANOVA) was run to investigate the effect of mother language, proficiency levels and their interaction on the performance on the translation test in order to probe the null-hypotheses. Based on the results displayed in Table 1. and 2. it can be concluded that there was a significant difference between the monolingual and bilingual groups' means on the Farsi-to-English translation $\left(\mathrm{F}(1,174)=8.12, \mathrm{p}=.005\right.$, Partial $\eta^{2}=.045$ representing a weak to moderate effect size). Thus the first null-hypothesis as the knowledge of Adjective order and placement in Azeri L1 did not affect the performance on Farsi-to-English translation by bilingual Azeri-Persian learners significantly more than monolingual EFL learners was supported.

As displayed in Table 2. The monolingual participants $(\mathrm{M}=9.97)$ significantly outperformed the bilingual group $(\mathrm{M}=8.98)$ on the translation test.

Concerning the second research question, there were significant differences between the high, mid and low proficie cy groups' means on the TT1 $(\mathrm{F}(2,174)=11.97, \mathrm{p}=.000$, Partial $\eta^{2}=.121$ representing an almost large effect size). As displayed in Table 3. high, mid and low proficiency groups' means were $10.45,9.61$ and 8.38 on the TT1.

The results of the post-hoc comparison tests (Table 4.) indicated that;

A: The high proficiency group $(\mathrm{M}=10.45)$ significantly had a higher mean than the low proficiency group $(\mathrm{M}=8.38)$ on Farsi-to-English translation ( $\mathrm{MD}=2.07, \mathrm{p}=.000$ ).

$\mathrm{B}$ : The mid proficiency group $(\mathrm{M}=9.61)$ significantly had a higher mean than the low proficiency group $(\mathrm{M}=8.38)$ on Farsi-to-English translation $(\mathrm{MD}=1.23, \mathrm{p}=.004)$.

$\mathrm{C}$ : There was not any significant difference between high $(\mathrm{M}=10.45)$ and mid $(\mathrm{M}=9.610$ proficiency groups means on Farsi-to-English translation $(\mathrm{MD}=.83, \mathrm{p}=.051)$.

Concerning the third research question, there was not any significant interaction between the mother language and proficiency levels on the Farsi-to-English translation $\left(\mathrm{F}(2,174)=.792, \mathrm{p}=.455\right.$, Partial $\eta^{2}=.009$ representing a weak effect size). Thus it can be concluded that the third null-hypothesis as proficiency levels did not significantly interact with the effect of mother languages was supported.
As displayed in Table 5. and figur 1. the order of means for both monolingual and bilingual groups were the same.

\section{DISCUSSION}

The present study examined L3A of English in a bilingual Azeri-Persian context. As was mentioned earlier, it tried to investigate how previous knowledge of a typologically similar and a typologically distant one, Persian as the L2 and Azeri as the L3 respectively, can affect the L3A of a language that shows a certain structural similarity with one of the previously acquired languages. The behavior of Azeri-Persian bilinguals was compared to that of Persian L2 learners of English.

With regard to the property focused, as was pointed out earlier, despite typological dissimilarity between Azeri (L1) and English (L3), both languages share the same structural similarity in the placement of adjectives pre-nominally. The results, however, did not reveal superiority of bilinguals over monolinguals in the test.

In general, the results from the acquisition of adjective placement in translation test indicate a non-facilitative effect from bilingual learners' second language, i.e. Persian. Such finding rules out the first introduced generative theory

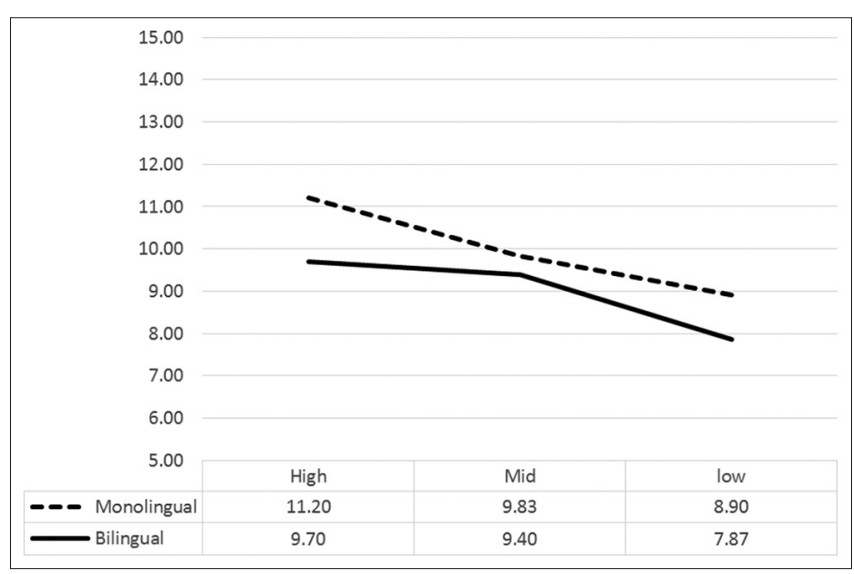

Figure 1. Interaction between mother language and proficiency on TT1

Table 1. Tests of between-subjects effects; TT1 by Mother Language and proficiency

\begin{tabular}{lcccccc}
\hline Source & Type III sum of squares & Df & Mean square & F & Sig. & Partial Eta squared \\
\hline Group & 44.006 & 1 & 44.006 & 8.123 & 0.005 & 0.045 \\
Prof & 129.733 & 2 & 64.867 & 11.974 & 0.000 & 0.121 \\
Group * Prof & 8.578 & 2 & 4.289 & 0.792 & 0.455 & 0.009 \\
Error & 942.633 & 174 & 5.417 & & & \\
Total & 17313.000 & 180 & & & & \\
\hline
\end{tabular}

Table 2. Descriptive statistics; translation by Mother Language

\begin{tabular}{|c|c|c|c|c|}
\hline \multirow[t]{2}{*}{ Group } & \multirow[t]{2}{*}{ Mean } & \multirow[t]{2}{*}{ Standard error } & \multicolumn{2}{|c|}{$95 \%$ confidence interval } \\
\hline & & & Lower bound & Upper bound \\
\hline Monolingual & 9.978 & 0.245 & 9.494 & 10.462 \\
\hline Bilingual & 8.989 & 0.245 & 8.505 & 9.473 \\
\hline
\end{tabular}


of L3A, CEM, which predicts positive or neutral effect of either L1 or L2. According to the CEM (Flynn et al. 2004), language acquisition is gradual and cumulative; and any prior language can either enhance subsequent language acquisition or have no effect. In other words, non-facilitative or negative transfer should never occur. Evidence for this model came from a study which examined the production of restrictive relative clauses with L3 learners of English with Kazakh as their L1 and Russian as their L2. Learners' L2 and L3 were similar in the structure whereas their L1 was different. Findings revealed a positive transfer from Russian L2.

As the findings of the present study show for the non-facilitative effect of the Persian L2, bilinguality does not show any advantage in the acquisition of English adjective placement despite the structural similarity between Azeri L1 and English L3. This finding is in line with Bardel and Falk (2007), Rothman (2011), Rothman and Cabrelli Amaro (2010) who criticize CEM on the ground that for the effect of L2 or typological proximity, transfer can be non-facilitative.

Moving to the next theory of L3 acquisition, TPM, for the structural similarity of Azeri and English in placing the attributive adjectives, a facilitative effect was predicted from the mother tongue of the bilinguals, but as the results revealed, bilinguals were heavily influenced by their second language and their L1 seemed to play no role in the acquisi-

Table 3. Descriptive statistics; translation by proficiency levels

\begin{tabular}{lcccc}
\hline Prof & Mean & Standard error & \multicolumn{2}{c}{$\begin{array}{c}95 \% \text { confidence } \\
\text { interval }\end{array}$} \\
\cline { 3 - 5 } & & $\begin{array}{c}\text { Lower } \\
\text { bound }\end{array}$ & $\begin{array}{c}\text { Upper } \\
\text { bound }\end{array}$ \\
\hline High & 10.450 & 0.300 & 9.857 & 11.043 \\
Mid & 9.617 & 0.300 & 9.024 & 10.210 \\
Low & 8.383 & 0.300 & 7.790 & 8.976 \\
\hline
\end{tabular}

tion of adjective placement. TPM, henceforth, could not account for the lower performance of bilingual learners. Point of genetic relatedness, as the other facet of the TPM, Azeri and English do not belong to the same language family (Altaic vs. Indo-European respectively), as a result, L1 did not play a significant role in the successful acquisition of a third language.

On the basis of the results obtained in the present study, one can claim that L2 had a stronger role than L1 in L3 acquisition of adjective placement. Hence, our findings seem to be in line with the claims of Bardel and Falk (2007), and Falk and Bardel (2011) who consider L2 as the transfer source independently of the structural similarity of the languages involved. In 2007, Bardel and Falk suggested that the L2 status factor (firstly introduced by Williamas \& Hammarbergs, 1998) could exert influence on the acquisition of L3 syntax. They conducted two main studies for approving such claim.

In the first study (Bardel and Falk, 2007), two groups' L3 acquisition of the placement of sentential negation in either L3 Swedish or Dutch were compared. One group had an L1 with V2 and L2 without V2, and the other group had an L1 without V2and an L2 with V2. This design made it possible to pinpoint the transfer source. The results demonstrated that the group with an L2 with V2 correctly transferred this structure into the L3, whereas the group, which had V2 only in their L1, did not transfer this structure. The authors explained this behavior by L2 transfer, and suggested that the L2 status factor (cf., Williams and Hammarberg, 2009 [1998]) enables L2 syntactic structures to be transferred into an L3, independently of the typology, and may block L1 transfer from appearing even though it would yield target-like structures.

In a later study by Falk and Bardel (2011), the L2 status factor was further tested on two groups of intermediate learners of German as an L3. One group had L1 English and L2 French and the other group had L1 French and L2 English. They tested the participants on the placement of object pronouns in German main and subordinate clauses, a design

Table 4. Multiple comparisons; Translation by proficiency Levels

\begin{tabular}{llccccc}
\hline (I) Profi & (J) Profi & Mean difference (I-J) & Standard error & Sig. & \multicolumn{2}{c}{ 95\% confidence interval } \\
\cline { 5 - 7 } & & & & & Lower bound & Upper bound \\
\hline \multirow{2}{*}{ High } & Mid & 0.83 & 0.425 & 0.051 & -0.01 & 1.67 \\
& Low & $2.07^{*}$ & 0.425 & 0.000 & 1.23 & 2.91 \\
\multirow{2}{*}{ Mid } & Low & $1.23^{*}$ & 0.425 & 0.004 & 0.39 & 2.07 \\
\hline
\end{tabular}

*. The mean difference is significant at the 0.05 level.

Table 5. Descriptive statistics; TT1 interaction terms

\begin{tabular}{lccccc}
\hline Group & Profi & Mean & Standard error & \multicolumn{2}{c}{ 95\% confidence interval } \\
\cline { 4 - 6 } & & & Lower bound & Upper bound \\
\hline Monolingual & High & 11.200 & 0.425 & 10.361 & 12.039 \\
& Mid & 9.833 & 0.425 & 8.995 & 10.672 \\
& Low & 8.900 & 0.425 & 8.061 & 9.739 \\
Bilingual & High & 9.700 & 0.425 & 8.861 & 10.539 \\
& Mid & 9.400 & 0.425 & 8.561 & 10.239 \\
& Low & 7.867 & 0.425 & 7.028 & 8.705 \\
\hline
\end{tabular}


which also makes it possible to detect the source of transfer (pronouns are pre-verbally placed in TL main clauses and in English, and post-verbally in TL subordinate clauses and in French). The results corroborated the presence of the L2 status factor noted in the 2007 paper, even at an intermediate proficiency level of the L3. They discussed the L2 status factor in terms of the similar cognitive conditions under which L2 and L3 are acquired (age of onset, learning situation and awareness of the learning process), whereas the L1 is acquired under different conditions and in a completely different way.

In the similar vein, Rothman and Cabrelli-Amaro (2010) compared the acquisition of French and Italian as either L2 or L3 learners. While Spanish and Italian are pro-drop languages, English and French are not. The data showed that properties of Null-Subject Parameter were not transferred from L1 English, but from L2 Spanish into L3 French or Italian. Importantly, this transfer is shown to be both positive (when there is a correspondence between L2 and L3) and negative (when there is no such correspondence). These results along with the findings of present study clearly dismissed the L1 transfer hypothesis in L3 acquisition, and corroborated the L2 status factor as proposed by Bardel and Falk (2007).

In Iran, Persian, as the language of instruction and media, enjoys a privileged status with respect to Azeri, minority language without a writing system. Bilingual learners are not literate in their mother tongue and such illiteracy along with the subtractive learning environment in Iran can lead to the lower performance of them in the present study.

The importance of literacy in the L1 and L2 has been widely discussed in several studies. Such studies, indeed, seem to point to superiority in language learning (Cenoz \& Valencia, 1994; Keshavarz \& Astaneh, 2004; Moghtadi, 2014; Sanz, 2000). Claiming that bilingual literacy has a stronger impact than bilingualism on L3 learning, Swain et al., (1990, as cited in De Angelis, 2007, p. 118) conducted a study with children studying in an English/French bilingual immersion program in Canada. Some of these children had acquired a heritage language in the home while others, in addition to having learned the heritage language in the environment, had also acquired literacy skills by attending heritage language programs. Learners' proficiency level in French was measured with a test which included writing, reading, speaking and listening components. The authors found that bilingualism has a positive effect on L3A, but only when coupled with the acquisition of literacy skills. They consequently claimed that "bilingual literacy has a crucial role in bringing about positive effects in third language learning" (Swain et al., 1990, as cited in De Angelis, 2007, p.118).

The other probable reason could be this fact that in cases where L 2 and L3 are learned in formal setting, as Giancaspro, Halloras, and Iverson (2015, p.13) put forward, the learning situation might be a further rationale for the L3 learner to classify her languages according to native language versus non-native languages (Williams and Hammarberg, 2009). As pointed out by Meisel (1983, p. 18), "previously learned second languages interfere with the learning of another foreign language" especially in the classroom setting. He further adds that there might be " a difference in the neuropsycho- logical basis for storing and processing first and second languages" and that if and when such difference can be shown, the distinction "first language" versus "other than first language" must be taken as crucial (p. 18).

To recapitulate, our results seem to be consistent with Falk and Bardel's (2010) categorization of language combinations studied under each hypothesis. The L2 status factor stems from research on language combinations that are neither very distant, nor very proximate, as is the case with this study; Persian and English are proximate in their language family, while Azeri and English share the structural similarity of adjective placement. The theory, however, is amendable in the acquisition of adjective placement.

\section{CONCLUSION}

The study investigated the effect of background languages on the acquisition of English adjective placement by Persian monolinguals and Azeri-Persian bilinguals. L3 proficiency and its interaction with participants' L1 were also considered and analyzed. Participants took an English proficiency test, a background questionnaire, and a translation task.

Based on the structural similarity of Azeri and English, bilingual learners were predicted to transfer positively from their L1 and surpass monolinguals in the acquisition of adjective placement. Results of the study, however, did not approve such expectation since monolinguals performed more significantly on translation test as a production test

The results did not support the CEM which predicts that both the L1 and L2 can supply the L3 with the appropriate feature value, in order to yield target-like structures. Nor did they support the TPM, which posits that for the structural similarity between Azeri and English, bilingual learners will be advantaged. In contrast, the data did support the LSFH, which predicts that the L2 will be favored as a source for CLI in L3 acquisition, even if transfer from L1 would lead to target-like structures. The LSFH therefore predicts that "transfer can both facilitate and hamper the acquisition of an L3" (Falk, submitted, p.113). As the results of this study revealed, the L2 acts like a filter in the acquisition of adjective properties and as a detriment does not permit the positive transfer of L1 structures into the L3. In general, L2 has played a non-facilitative role in this situation, and has proved to be stronger than the typology factor in L3 acquisition.

Moving to proficiency level and its interaction with mother tongue, although proficiency in the L3 proved to have a positive effect on the acquisition of adjective properties, it did not confirm to have any effect on the mother tongue, i.e., bilinguality or monolinguality of the participants. The reason could be the difficulty level of the structures, especially the adjective order, for both monolinguals and bilinguals.

The first reason for such an unexpected result could be the type of bilingualism which is dominant in Iran, i.e. subtractive bilingualism. In our country, Azeri-Persian bilinguals learn their L1 only orally in a naturalistic setting. They do not receive schooling in their mother tongue and their academic language is Persian, the native language of the majority linguistic groups. So it can be argued that Persian is the 
more dominant language among the bilinguals (Bahrainy, 2007, p. 17). M. Thomas (1992) also argued that language dominance was a crucial factor in her unexpected results. Maghsoudi (2010) also reiterated that his bilingual participants' lower performance could be attributed to the context in which they have acquired their L1.

The second reason for such finding which is directly related to the theory of dominant language, is Cummins' (1979) Developmental Interdependence Hypothesis. The theory predicts a positive correlation between acquiring of literacy skills in L1 and their acquisition of L2, and by extension L3 properties. For lack of such literacy skills in Azeri L1 among Azeri-Persian bilinguals in Iran, they are claimed to suffer from "age-appropriate" skills in their L3. As Maghsoudi (2010) believes "If the first language is poorly developed for various reasons, then exposure to L2 impedes a child's competence in his continued development in L1, which itself has a detrimental effect on the child's progress in L2 or L3" (p. 178).

The other probable reason for such low performance of bilinguals might be that Persian and English share the same language family (Indo-European), whereas Azeri belongs to a totally different language family, i.e. Altaic, with no resemblance to English or Persian. As results indicated Persian, for its genetic relatedness with English played the role of the source language in a negative way, that of non-facilitative CLI.

In sum, clear evidence has been found pointing to little transfer from L1 Azeri into L3 English, despite depicting structural similarity with respect to English adjective placement. There were significant differences between bilinguals and monolinguals in translation test. It was also revealed that there was great improvement in the learners' performance on the test as their proficiency level increased to advanced levels. In other words, our results provide evidence pointing to a strong L2 effect and no trace of L1 Azeri interlanguage transfer in Azeri speaking learners in L3 acquisition of English adjective properties. The present study is mostly in line with Bardel \& Falk (2007), Chin (2009), Falk \& Bardel (2011), and Rothman \& Cabrelli-Amaro (2010) who unanimously point to L2 as the determining factor in the acquisition of an L3.

\section{REFERENCES}

Bahrainy, N. (2007). Bilinguality: An enhancement or a hindrance. Pazhuhesh-e Zabanha-ye Khareji. 32, 5-21.

Bardel, C., \& Falk, Y. (2007). The role of the second language in third language Acquisition: The case of Germanic syntax. Journal of Second Language Research, 23(4), 459-484. http://dx.doi.org/10.1177/0267658307080557

Bardel, C. \& Lindqvist, Ch. (2007). The role of proficiency and psychotypology in lexical cross-linguistic influence. A study of a multilingual learner of Italian L3. Retrieved from http://www.isd.su.se

Berkes, E, \& Flynn, S. (2012). Enhanced L3...Ln acquisition and its implications for language teaching. In D. Gabrys-Barker (Ed.), Cross-linguistic influences in multilingual language acquisition (pp. 1-22). Berlin:
Springer.

Cenoz, J. (2001). The effect of linguistic distance, L2 status and age on cross-linguistic influence in third language acquisition. In J. Cenoz, B. Hufeisen, \& U. Jessner, (Eds.), Cross-linguistic influence in third language acquisition: psycholinguistic perspectives (pp. 8-20). Clevedon, Buffalo, Toronto, Sydney: Multilingual Matters Ltd.

Cenoz, J. (2003). The additive effect of bilingualism on third language acquisition: A review. International Journal of Bilingualism, 7 (1), 71-87. http://dx.doi.org/10.1177/13 670069030070010501

Cenoz, J. (2008). The influence of bilingualism on multilingual acquisition: Some data from the Basque country. Retrieved from http://wehs.uvigo.es

Cenoz, J. (2009). Towards multilingual education: Basque educational research in international perspective. Bristol, Buffalo, Toronto: Multilingual Matters Ltd.

Cenoz, J. and Jessner, U. (Eds.). (2000). English in Europe: The acquisition of a third language. Clevedon, Buffalo, Toronto, Sydny: Multilingual Matters Ltd.

Cenoz, J. and Jessner, U. (Eds.). (2001). Trends in bilingual acquisition. Amsterdom: John Benjamins. http://dx.doi. org/10.1075/tilar. 1

Chin, H.J. (2009). Language transfer in the acquisition of the semantic contrast. In Y.-k.I. Leung (Ed.), Third language acquisition and Universal Grammar (pp. 30-54). Clevedon, Buffalo, Toronto, Sydney: Multilingual Matters Ltd.

Crystal, D. (2010). The Cambridge encyclopedia of language. Cambridge and New York: Cambridge University Press.

De Angelis, G. (2007). Third or additional language acquisition. Clevedon, Buffalo, Toronto: Multilingual Matters Ltd.

De Angelis, G., \& Selinker, L. (2001). Interlanguage transfer and competing linguistic systems in the multilingual mind. In J. Cenoz, B. Hufeisen \& U. Jessner (Eds.), Cross-linguistic influence in third language acquisition: Psycholinguistic perspectives (pp. 42-58).

Dewaele, J-M. (2001). Activation or inhibition? The interaction of L1, L2 and L3 on the language mode continuum. In J. Cenoz, B. Hufeisen, \& U. Jessner, (Eds.), Cross-linguistic influence in third language acquisition: psycholinguistic perspectives (pp. 69-89). Clevedon, Buffalo, Toronto, Sydney: Multilingual Matters Ltd.

Erfani, P. (2012). Azeri morphosyntactic variation: The effect of Persian on NP structures. Retrieved from http:// studentorgs.utexas.edu

Falk, Y. (submitted). The impact of the L2 status factor on the acquisition of German as an L3. A study of adverb placement. Retrieved from http://www.lotpublications.nl

Falk, Y. \& Bardel, C. (2010). The study of the role of the background languages in third language acquisition. The state of the art. Retrieved from http://repository. ubn.ru.nl

Falk, Y. and Bardel, C. (2011). Object pronouns in German L3 syntax: Evidence for the L2 status factor. Retrieved from http://repository.ubn.ru.nl

Fallah, N., Jabbari, A.A., \& Fazilatfar, A.M. (2016). 
Source(s) of syntactic CLI: The case of L3 acquisition of English possessives by Mazandarani-Persian bilinguals. Second Language Research, 32, 225-245.

Giancaspro, D. Halloran, B., \& Iverson, M. (2015). Examining L3 transfer: The acquisition of differential object marking in L3 Brazilian Portugeses. Bilingualism. Language and Cognition, 18, 191-207. Doi: 10.1017/ S1366728914000339

Gooniband Shooshtari, Z. (2009). Generative syntactic transfer in L2 and L3 acquisition via the channel of translation. English language Teaching, 2 (1), 129-149.

Hammarberg, B. (2001). Roles of L1 and L2 in L3 production and acquisition. In J. Cenoz, B. Hufeisen, \& U. Jessner, (Eds.), Cross-linguistic influence in third language acquisition: psycholinguistic perspectives (pp. 21-41). Clevedon, Buffalo, Toronto, Sydney: Multilingual Matters Ltd.

Hermas, A. (2010). Language acquisition as computational resetting: Verb movement in L3 initial state. International Journal of Multilingualism, 7 (4), 343-362. http:// dx.doi.org/10.1080/14790718.2010.487941

Hermas, A. (2015). The categorization of relative complementizer phrase in third-language English: a feature re-assembly account. International journal of Bilingualism, 7, 343-362.

Jabbari, A.A, \& Salimi, H. (2015). L3 acquisition of simple and present progressive tenses by Iranian EFL learners. SAGE open, 5(4), 1-8. http://doi. org $/ 10.1177 / 2158244015615163$

Jaensch, C. (2010). L3 acquisition of German adjectival inflection: A generative account. Journal of Second Language Research, 27 (1), 83-105. http://dx.doi. org/10.1177/0267658310386646

Jin, F. (2009). Third language acquisition of Norwegian objects: Interlanguage transfer or L1 influence? In Y-K. I. Leung (Ed.), Third language acquisition and Universal Grammar (pp. 144-161). Clevedon: Multilingual Matters.

Keshavarz, M. H., \& Astaneh, H. (2004). The impact of bilinguality on the learning of English vocabulary as a foreign language (L3). Bilingual Education and Bilingualism, 7 (4), 295-302. http://dx.doi. org/10.1080/13670050408667814

Khodabandeh, F. (2013). Cross-Linguistic Influence in Third Language Acquisition: Acquisition of syntactic structures by students Bilingual in Persian-Azerbaijani, Persian- Armenia, and Persian-Gilaki. International Journal of English Language \& Translational Studies, 1 (3), 136-165.

Kujalowicz, A. (2005). Cross-linguistic influence in the production of Germanprepositions by Polish learnersof English and German. Studia Anglica Posuaniensia, 41, 187-198.

Lindqvist, Ch. (2009). The use of the L1 and the L2 in French L3: examining cross-linguistic lexemes in multilingual learners' oral production. International Journal of Multilingualism, 6(3), 281-297. http://dx.doi. org/10.1080114790710902812022
Maghsoudi, M. (2010). The interaction between bilingualism, educational and social factors and foreign language learning in Iran. Journal of Language and Culture, 1 (13), 35-46.

M. Meisel, J. (1983). Transfer as a second-language strategy. Language and Communication, 3, 11-46. Doi: 10.1016/0271-5309 (83) 90018-6

Modirkhamene, S. (2008). Metalinguistic awareness and bilingual vs. monolingual EFL learners: Evidence from a diagonal bilingual context. The Journal of Applied Linguistics, 1 (1), 66-102.

Moghtadi, L. (2014). The effect of bilingualism on the acquisition of English syntactic structures: evidence from relative clause. Unpublished $\mathrm{PhD}$ dissertation, Khorasgan (Isfahan) Azad University.

Moghtadi, L., Koosha, M., \& Lotfi, A.R. (2014). Learning of relative clauses By L3 learners of English. Applied Research on English Language, 4 (1), 79-105.

Noves, T., Miralpeix. L. and Celaya, M.L. (2005). Who transfers more... and what? Crosslinguistic influence in relation to school grade and language dominance in EFL. International Journal of Multilingualism, 2(2).

Ortega, M. (2008). Cross-linguistic influence in multilingual language acquisition: The role of L1 and non-native languages in English and Catalan oral production. Ikala, revista de lenguajey cultura, 13 (19), 121-142. http:// www.redalyc.org/articulo.oa? $\mathrm{id}=255020449007$

Rothman, J. (2010). On the typological economy of syntactic transfer: word order and high/low attachment preference in relative clause interpretations in L3 Brazilian Portuguese. International Review of Applied Linguistics in Language Teaching, 48 (2-3), 245-275. Abstract obtained from Walter de Gruyter GmbH \& Co. KG, 2010, 48, http://http://www.uiowa.edu

Rothman, J. (2011). L3 syntactic transfer selectivity and typological determinacy: The typological primacy model. Second Language Research, 27 (1), 107-127. http://dx. doi.org/10.1177/0267658310386439

Rothman, J. (2013). Cognitive economy, non-redundancy and typological primacy in L3 acquisition: Evidence from initial stages of L3 Romance. In S.Baauw, F. Dirjkoningen, \& M. Pinto (Eds), Romance languages and linguistic theory (pp. 217-247). Amsterdom: Benjamins.

Rothman, J. (2015). Linguistic and cognitive motivation for the Typological Proximity Model (TPM) of third language (L3) transfer: Timing of acquisition and proficie cy considered. Bilingualism: Language and Cognition, 18, 1-12. Doi: 10.1017/S136672891300059x

Rothman, J., \& Cabrelli, J. (2009). What variables condition syntactic transfer? A look at the L3 initial state. Journal of Second Language Research, 25(4), 1-30.

Sanz, C. (2000). Bilingual education enhances third language acquisition: Evidence from Catalonia. Journal of Applied Psycholinguistics, 21, 23-44.

Schwartz, B.D., \& Sprouse, R. (1996). L2 cognitive states and the full transfer/full access hypotheses. Second Language Research, 12 (1), 40-72.

Shomoossi, N., Shomoossi, A, \& Yazdi, F. (2013). A gram- 
mar profile of English, Persian and Azeri Turkish: a brief reference to L3 acquisition. Journal of Education, 2 (1), 51-57.

Slabakova, R., \& Garcia Mayo, M. delP. (2015). The L3 syntax-discourse interface. Bilingualism: Language and Cognition, 18(2), 208-226.

Tremblay, M.-C. (2006). Cross-linguistic influence in third language acquisition: The role of L2 proficiency and L2 exposure. CLO/OPL, 34, 109-119.
Westergaard, M., Mitrofanova, N., Mykhaylyk, R., \& Rodina, Y. (2016). Crosslinguistic influence in the acquisition of a third language: The linguistic proximity model. International Journal of Bilingualism, 1-17. Doi: $10.1177 / 1367006916648859$

Williams, S., \& Hammarberg, B. (1998). Language switches in L3 production: Implications for a polyglot speaking model. Applied Linguistics, 19, 295-333. 